\title{
Influence of Electronic Commerce on accounting basic assumptions Jingsen Hua ${ }^{*}$ \\ Nanjing University of Science and Technology, China \\ *Corresponding author: Jingsen Hua,postgraduate,huajingsen@126.com
}

\begin{abstract}
As electronic commerce is developing constantly in our country,social transactions is no longer completed only through the traditional paper-based documents and goods,but the full utilization of product information online and the convenient fund settlement system. This mode of transaction has prompted a lot of enterprises to realize electronic and paperless accounting methods,and these changes will inevitably have a profound impact on China's traditional accounting theory.In this paper,based on the development trend of electronic commerce,the impact of electronic commerce on accounting theory is discussed from the four aspects of the basic assumptions of accounting.
\end{abstract}

Key words: electronic commerce; accounting theory; accounting basic assumption; influence; transaction

\section{Introduction}

Electronic commerce is a new type of business model which is booming in the late 20th Century. It works with electronic technology,network connection technology and modern communication technology,so that the parties involved in the transaction can achieve electronic in the whole process through electronic means.

According to the situation statistics of China's Internet network development ,which is released by the Chinese Internet Network Information Center (CNNIC) in 2015,shows that China's online consumers has reached 194 million in 2014,and the percentage of online shopping usage has increased to $37.8 \%$. Data shows that China's electronic commerce has developed rapidly,transactions of electronic commerce also showed a linear growth.

The traditional accounting theory is established and improved in the era of industrial economy. With the emergence of new business operating model of electronic commerce,it has a significant impact on the traditional accounting theory. ${ }^{1}$

Accounting hypothesis,also known as accounting assumptions,are reasonable judgments of the social and economic environment where accounting works. They're the prerequisites of accounting. After extensive discussion at the early stage of the accounting profession in the 1980s to mid 1990s,the Ministry of Finance of China issued "accounting standards for business enterprises" in 1992 by the four fundamental accounting assumptions:accounting subject,continuous operation,accounting period and monetary measurement,and still in use nowadays. The four accounting assumptions are based on the social and economic environment of the industrial society,and on the basis of these,the existing financial accounting model is established. ${ }^{2}$ At present,the wide application of electronic commerce especially the appearance of virtual enterprises has made great changes to the social and economic environment which original accounting basic assumptions based on,so that the basic assumptions of accounting theory have the new meanings and significance. 


\section{Influence of electronic commerce on accounting basic assumptions \\ 2.1 Influence on accounting subject assumption}

Accounting subject, also known as the accounting entity, refers to a specific company or organization the accounting information reflects, and standardizes the scope of the accounting. It provides the basis for determining the economic resources and operations of the specific enterprises. The traditional accounting theory emphasizes that accounting subject is a stable and independent operating unit.The judgment of accounting entity are based on the following two points: the first is the control of resources and obligations and the economic unit of operation; the second is the scope of the economic interests of the particular person, group or organization. Accounting subject assumption was put forward with the emergence of a large number of profit organization. The purpose is to separate the company as an independent economic entity, and distinguish it from other economic organizations and the economic activities of the owners. This assumption is mainly to clear the spatial extent of a corporate accounting object, so that accountants can clearly distinguish the business transactions from the owners' activities, and its basis of determination is the economic responsibility of the administration management and economic activities the economic units should take. Specifically, the assumption of the traditional accounting theory is the accounting subject refers to the enterprises' scope of accounting recognition, measurement and reporting. More specifically, the main performance of the accounting subject has a certain amount of funds, independent production and business activities and other activities and the implementation of independent accounting.

The development of electronic commerce has broken through the traditional space.In order to achieve a goal,it can form a temporary alliance of computer network in a short period of time.There are no geographical boundaries, no fixed form, no spatial extent, no physical office space, fixed assets and employees and there is only a combination of an abstract concept. Composition of each independent enterprise can make use of computer network and add or cut down groups at any time according to the actual situation, especially free combination of management subjects according to different transactions , a subject is likely to dissolve after the completion of an economic transaction, and it is likely in the next transaction in accordance with the requirements of its capital, technology and knowledge we need a new subject, which is obviously different from traditional entity in the organization and operation,and it makes accounting entity identification difficult. In the cyberspace, the virtual enterprises are formed and dissolved rapidly, which makes the accounting subject to be diversified and uncertain, so that the accounting subject is difficult to define. If the accounting entity is not sure, assets, liabilities, income, expenses and other accounting elements have no room for the ownership, accounting information users can not understand the accounting information reflected by the financial reports. ${ }^{3}$

Therefore, we need to take the accounting entity as a relative concept, to determine the internet company as the virtual accounting entity: a temporary alliance of independent legal entities on the computer network. Replace the traditional accounting subject assumption with the relative accounting subject assumptions, so that we can determine the spatial extent in the era of electronic commerce accounting, confirm and measure accounting elements such as assets, liabilities, incomes and expenses correctly, providing the right accounting information to the users.So the main body of accounting in electronic commerce is relative, which should 
be determined by the needs of the business. ${ }^{4}$ The accounting subject of the traditional accounting theory is no longer stable, and its structure and function are not stable,too.

\subsection{Influence on continuous operation assumption}

The continuous operation assumption refers to the production and business activities of the accounting subject will indefinitely continue. In the foreseeable future,accounting subject won't disappear nor cut business massively because of liquidation, dissolution and bankruptcy. Only under this assumption, the reproduction of the enterprise can be carried out, the enterprise's capital can cycle normally, accounting can use historical costs rather than the production price to confirm. The hypothesis considers the business entities will continue its activities until the realization of their fiduciary responsibility.Each subject are not expected to be liquidated, reorganized or merged. In view of this, the assumption reflects the subject has the desire to intend to a long-term operation. Continuous operation was proposed under the condition of market economy. As the main body of accounting, there are competitions between enterprises. So their operating periods are uncertain, But the accounting information provided should be based on continuous operation. Otherwise, some basic methods of handling basic accounting information can not be used. The assumption of continuous operations makes rules for the time of the normal accounting activities. This assumption is mainly to make the accounting information processing principles and procedures to maintain consistency and stability.

In the age of electronic commerce, virtual enterprises use modern information technology to break the time intervals.Virtual enterprise can not only operate in a long period, but also be dismissed soon.More enterprises may add or reduce the combination according to the actual situation. In practice, the rapid development and improvement of the existing electronic commerce market makes the online business face greater pressure. At the same time the temporary suppliers and customers involved in this transaction model will also enhance the uncertainty of continuous operations. Uncertainty in the operation makes the process of accounting business in the future more difficult. The fierce market competition environment has greatly shortened the time limit of accounting, and even makes the enterprises have the possibility of liquidation and termination at any time.

In view of this, electronic commerce extends the connotation of the continuous operation hypothesis.Because the duration of business has great uncertainty, it was assumed that business can be operated continuously.So that the accounting principles, accounting procedures and methods based on the basis of continuous operation. Virtual enterprise has poorer stability than traditional enterprise and can be dissolved more easily, but the purpose of its existence is consistent with the traditional enterprise, the information users's demand to get the financial information is same with with the traditional enterprise. ${ }^{5}$

\subsection{Influence on accounting period assumption}

The assumption of the traditional accounting theory to the accounting period is that the continuous production and operation process of the enterprise should be divided into shorter periods. The purpose of the accounting period is to balance the profit and loss and to make up the financial accounting report in time, so as to provide timely information about the financial position, operating results and cash flow of the enterprise. Accounting period is usually one 
year, known as the accounting year or fiscal year. The accounting period is actually a supplement to the continuous operation hypothesis. A series of accounting principles, such as the realization of revenue and the ratio of the cost, are all based on the assumption of the accounting period and the continuous operation hypothesis.

With the development of Internet and electronic commerce information technology,traditional annual staging of the accounting period assumptions will be affected.Powerful computing and transmission function can let the financial management from static to dynamic, accounting from hindsight to real time and the accounting period assumption eliminate the time limit. But in order to distinguish the various operating results during the operation,the hypothesis of accounting period set up four special accounting procedures as the "accrued", "deferred", "prepaid", "withholding" to deal with the assets of accounts receivable, accounts payable, depreciation, amortization and other accounting issues. Even if the accounting information is provided by the electronic commerce environment, the book value of the assets are disclosed on the base of the accounting period. ${ }^{6}$ The development of the information management system and the maturity of the information technology can not be separated from the time range to talk about the information. The electronic commerce will provide real-time accounting information for the information users with no doubt, but the real-time changes of the accounting information will also make the user confused to understand the information. In order to adapting to the real-time character of accounting information disclosure in the electronic commerce environment, we can consider shortening the traditional accounting period to quarter or month, but the abolition of accounting period assumptions is not desirable. The timeliness and comprehensiveness of data processing in the era of electronic commerce makes the financial report use the real-time reporting system. Accordingly,the requirements of different management subject to the accounting information are different, so accounting period should be based on their needs. ${ }^{7}$

\subsection{Influence on monetary measurement assumption}

The monetary measurement assumption refers to taking money as the main unit of measurement, to measure, record and report the production and operation activities of the accounting entity in the process of accounting. Monetary measurement has two meanings: firstly, money is the best unit of measurement in many units of measurement; secondly,the value of money is stable. As the common measure of accounting measurement, currency is conducive for different companies, different industries to use the same caliber to reflect the financial position and operating results.It is also conducive to the users of accounting information to analyze information and make correct decisions.

The development of electronic commerce has a significant impact on monetary measurement assumption.With the development of electronic commerce,although human capital, knowledge capital, goodwill and other intangible assets has become the main source of profit and the key factors for the development of enterprises, it is difficult to use the traditional currency to confirm and measure. Therefore,non monetary measurement model should be introduced into enterprises to improve the usefulness and relevance of accounting information. ${ }^{8}$ The application of electronic money has enlarged the extension of money measurement. Electronic currency is the inevitable product of the electronic commerce environment. It refers to the credit currency which use means of communication and 
electronic technology and reflect value of commodity with the legal monetary unit in the credit card market for circulation. Though electronic money is unlike traditional money distributed by the government and forced to circulate,it is issued by a bank and for voluntary use and its role in electronic commerce activities is similar with the role of money in daily life, as a measurement of value in commodities trading. Electronic money is the conceptual money, but its essence and other means of payment are the same as the currency.

\section{Conclusion}

Accounting basic assumption is made on economic activity in the specific economic environment, and the emergence and development of the electronic commerce have made great changes on the social economic environment,which requires the accounting basic assumption should be adapted to the changes of social economic environment and make corresponding adjustments and changes.

Overall, although there are no large qualitative changes for the accounting environment, emergence of some new features have a large breakthrough for accounting basic assumption in traditional accounting theory. ${ }^{9}$ So we need to make a new interpretation and some new extension of the connotation for accounting basic assumption in traditional accounting theory, such as the subject of accounting assumption should involve both real and virtual subject,continuous operation assumption under the electronic commerce environment evolve into the limited continuous operation,accounting period assumption should meet the needs of reality and money measurement assumption means we not only use money to measure value of commodities but also electronic metering unit at the same time.

\section{References}

1. J.B. Zhao, A discussion about the impact of Electronic Commerce on financial accounting, Journal of Shanxi University of Finance and Economics.2 (2007) 31-33.

2. M.L. Zhuang, Electronic commerce accounting research. Chinese Financial and Economic Publishing House.Beijing,2014.

3. Q. Li, Analysis of sales revenue accounting under the background of electronic commerce,Communication of Finance and Accounting.16 (2015) 89-90.

4. Y.R. Zhang, Y. Feng, Research on the influence of Electronic Commerce on the traditional accounting theory and methods,Communication of Finance and Accounting.1 (2011) 21-24.

5. W.H. Tan, Innovation of accounting theory based on e-commerce,Communication of Finance and Accounting.21 (2011) 26-29.

6. J.F. Lin, Analysis of the influence of Electronic Commerce on accounting theory,China Market.2 (2016) 118-119.

7. X.J. Liu, A number of issues in the e-commerce environment,Journal of Commercial Economics.18 (2004) 29-32.

8. Q.J. Xu, G.J. Liu,The problems we should pay attention to in e-commerce accounting,Finance and Accounting Monthly.7 (2013) 58-59.

9. L.K. Li, SWOT analysis and countermeasure research on the development of electronic commerce accounting,Commercial Accounting.12 (2016) 108-110. 